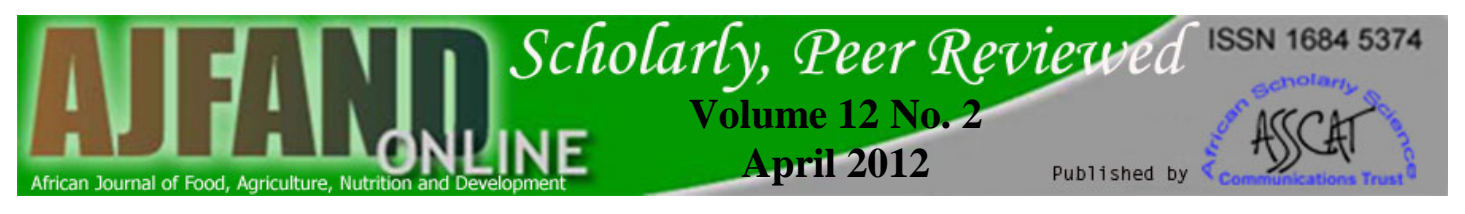

\title{
INFANT AND YOUNG CHILD FEEDING (IYCF) PRACTICES IN ETHIOPIA AND ZAMBIA AND THEIR ASSOCIATION WITH CHILD NUTRITION: ANALYSIS OF DEMOGRAPHIC AND HEALTH SURVEY DATA
}

$$
\text { Disha } \mathrm{AD}^{* 1,2} \text {, Rawat } \mathbf{R}^{2} \text {, Subandoro } \mathrm{A}^{2} \text { and } \mathbf{P} \text { Menon }^{2}
$$

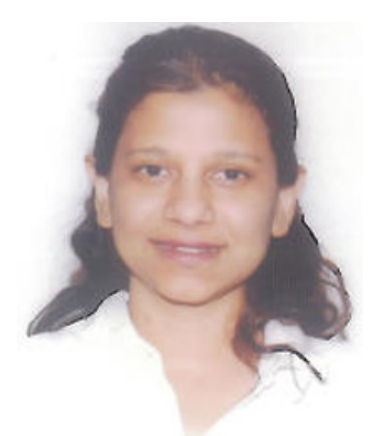

Ali Disha

*Corresponding author email: d.ali@cgiar.org

${ }^{1}$ Affiliation: Poverty, Health and Nutrition Division, International Food Policy Research Institute, 2033 K. St., NW, Washington DC 20006, USA.

${ }^{2}$ House 1320, Kebele 03/05, Lideta sub-city, Addis Ababa, Ethiopia. 


\section{ABSTRACT}

Data from the 2005 Ethiopia Demographic and Health Survey (EDHS) and the 2007 Zambia Demographic Health Survey (ZDHS) were analyzed to examine the association between World Health Organization (WHO) recommended IYCF indicators and nutritional status among children 0-23 months of age in Ethiopia and Zambia. A total of 1810 and 2512 children within this age group from Ethiopia and Zambia, respectively, were included in the analysis. Exclusive breast-feeding among children 0-5.9 months of age is low in both Ethiopia (43\%) and Zambia (51 \%). Timely introduction of complementary food is lower in Ethiopia (61 \%) compared to Zambia (90\%). Only 7 percent of children between 6-23 months of age consumed diets that met the minimum dietary diversity requirement of four or more food groups consumed per day compared to $37 \%$ in Zambia. Multiple linear and logistic regression analyses using appropriate measures to account for the complex survey design were applied to examine the associations between IYCF practices and child anthropometry. Linear regression results show that exclusive breast-feeding (EBF) is positively associated with weight-for-height z-score (WHZ) (effect size (ES) 0.65; $\mathrm{p}<0.001$ ) and weight-for-age $\mathrm{z}$-score (WAZ) (ES 0.28; $\mathrm{p}<0.01$ ) in Zambia. In Ethiopia, EBF under 6 months of age is negatively associated with height-for-age zscore (HAZ) (ES 0.81; $\mathrm{p}<0.01$ ). Timely introduction of complementary food between 6-8 months of age was positively associated with HAZ (ES 1.19; $<<0.01$ ) in Zambia. Higher dietary diversity score was associated with higher HAZ (ES 0.23, $\mathrm{p}<0.001$ in Ethiopia; ES 0.12, p $<0.01$ in Zambia) and WAZ (ES 0.17, $\mathrm{p}<0.001$ in Ethiopia; ES $0.04, \mathrm{p}<0.10$ in Zambia) in both countries. The findings demonstrate the need to reinforce age- appropriate IYCF practices to address child undernutrition. Special attention is needed to improve the complementary feeding practices, particularly diet diversity for children 6-23 months of age, while sustaining a focus on EBF among children under 6 months of age, in order to improve overall nutritional status of young children in Ethiopia and Zambia.

Key words: anthropometry, IYCF indicators, Ethiopia, Zambia 


\section{INTRODUCTION}

The prevalence of childhood undernutrition is high in many low-income countries particularly in regions of Asia and sub-Saharan Africa [1]. More than a third of child deaths globally, and more than ten percent of the total global disease burden are attributable to maternal and child undernutrition [1, 2]. Apart from contributing to childhood disease burden [2], early undernutrition has long lasting effects on physical as well as cognitive growth into adulthood [3]. In addition to its direct relation to the first Millennium Development Goal (MDG 1), namely, eradicating extreme poverty and hunger, reducing undernutrition is also a key factor underpinning several other MDGs.

While economic and contextual factors are strong determinants of child nutritional status $[4,5,6]$, immediate causes such as feeding practices are associated with nutritional outcomes, particularly stunting, independent of socio-economic determinants [7,8]. Even with optimum breast-feeding, children are at risk of being stunted if adequate quantity and quality of complementary food is not given beginning at 6 months of age. Recognizing the role of infant and young child feeding practices on the nutritional status of children under two years of age, the World Health Organization (WHO) developed and validated a set of core indicators to assess infant and young child feeding (IYCF) practices [9]. These indicators encompass both breast-feeding and complementary feeding related practices. A particular challenge related to age-appropriate complementary feeding is ensuring adequate diet quality through an appropriately diverse diet [10]. Low diet diversity is associated with stunting in other studies [7, 8].

The determinants of three manifestations of anthropometric failure of stunting, underweight and wasting can be quite different, requiring different types of interventions [1,11]. Nevertheless, all three manifestations are high among young infants. An analysis of 19 Demographic and Health Surveys (DHS) indicated that prevalence of severe wasting was higher at younger ages and declined by 24 months while stunting prevalence peaks around 24 months and plateaus at a high level thereafter [1]. It is important, therefore, to examine the role of IYCF practices in relation to all three indicators.

The objective of this paper is to compare IYCF practices and their association with child undernutrition in two African countries, Ethiopia and Zambia. These two countries are included in this analysis in the context of designing appropriate interventions in both countries where IYCF related projects are being implemented. Both countries have a high prevalence of stunting, yet their profiles of wasting and underweight differ $[12,13]$.

\section{METHODS}

\section{Data and sample}

Data from the 2005 Ethiopia Demographic Household Survey (EDHS), and the 2007 Zambia Demographic Household Survey (ZDHS) were used to address our objectives 
$[12,13]$. Both DHS datasets provide the most current nationally representative household and child level data and include IYCF and child anthropometric data collected according to WHO guidelines [14]. The key IYCF indicators examined are presented in Table 1.

Children 0-23 months of age were included in this analysis; this age group relates to the construction of each age-appropriate IYCF indicator. Only cases with complete anthropometric measurements at the time of the survey are included in the analysis. The total sample size included in this analysis is 1810 children from Ethiopia and 2512 from Zambia aged 0-23 months of age.

\section{Variables}

The dependent variables capturing child nutritional status were modeled both as continuous and categorical variables. The continuous variables included height-forage $\mathrm{Z}$ score (HAZ), weight-for-height $\mathrm{Z}$ score (WHZ) and weight-for-age Z score (WAZ). Categorical variables to capture stunting, wasting and underweight were created from the continuous variables if HAZ, WAZ and WHZ were 2 standard deviations below the population median.

The independent variables used in our analyses are presented in Table 1. These variables were constructed using the definitions and measurements recommended by the WHO guidelines for infant and young child feeding. Early initiation of breastfeeding was measured based on historic recall by all mothers who had children between 0-23 months of age. Introduction of complementary feeding was measured among infants between 6-8 months of age who were receiving solid, semi-solid or soft foods. Minimum dietary diversity was estimated by recall of food and liquid consumption during the previous day of the survey. A dietary diversity score was created by summing consumption of seven types of food groups: i) grains, roots, tubers; ii) legumes and nuts; iii) dairy products; iv) flesh foods (meat, fish, poultry, organ); v) eggs; vii) vitamin A-rich fruits and vegetables, and viii) other fruits and vegetables. Thus the dietary diversity score ranges from $0-7$ with minimum of 0 if none of the food group is consumed to seven if all the food groups are consumed. From the dietary diversity score, the minimum dietary diversity indicator was constructed using the WHO recommended cut-off point with a value of " 1 " if the child had consumed four or more groups of foods and "0" if less.

\section{Analyses}

Data analyses were conducted using Stata 11 statistical software (Stata Corp). Sample weights and specific survey commands were applied to all analyses to account for the complex survey design and to appropriately correct standard errors for all analyses. Descriptive analyses were first conducted to present general information of the study population. To assess the association between undernutrition and IYCF indicators, linear regression analysis was used for continuous dependent variables (HAZ, WHZ, WAZ) and logit regression analysis was used for binary dependent variables (stunting, underweight, wasting). Regional level variability was controlled in the models using regional level dummy variables. A number of potential confounding factors at the child, maternal and household levels which were likely to influence the 
nutritional outcomes of children were also included in all models. These included: (i) age and gender of the child; (ii) maternal height, BMI, maternal education, and utilization of prenatal care; (iii) and household wealth status. Each regression model used the age-group of children relevant to the specific IYCF indicator being tested.

Descriptive and multivariate analyses were conducted using Stata 11 statistical software (Stata Corp). Since DHS surveys use multistage cluster sampling methods, survey weights and survey-specific commands (svy in Stata 11) were applied to account for the complex survey design and to appropriately correct standard errors for all analyses. To assess the association between undernutrition and IYCF indicators, ordinary least squares (OLS) regression analysis was used for continuous dependent variables (HAZ, WHZ, WAZ) and logit regression analysis was used for categorical dependent variables (stunting, underweight, wasting). Regional level variability was controlled in the models using regional level dummy variables. A number of potential confounding factors at the child, maternal and household levels which were likely to influence the nutritional outcomes of children were also included in all models. These included: (i) age and gender of the child; (ii) maternal height, BMI, maternal education, and utilization of prenatal care; (iii) and household wealth status. Each regression model used the age-group of children relevant to the specific IYCF indicator being tested.

\section{RESULTS}

\section{Sample characteristics}

Table 2 presents the general characteristics of the two study populations. Both study populations were mainly rural, with a significantly larger rural population in Ethiopia (93 \% in Ethiopia vs.72 \% in Zambia). In Zambia $16 \%$ of households were headed by females compared to $11 \%$ in Ethiopia. Households in both the Zambia and Ethiopia data sets had limited access to clean water within the premises. However, one major difference between the two countries was the availability of sanitation facilities. Over $60 \%$ of the population in Ethiopia did not have any sanitation facilities compared to $27 \%$ of the Zambian population. Maternal characteristics also varied between the two countries. Over three-quarters (77\%) of the mothers did not have any education in Ethiopia compared to only $14 \%$ in Zambia. Mothers in Ethiopia were also much less likely to have had antenatal care during pregnancy than mothers in Zambia (30 \% vs. 98 \%). About $20 \%$ of the mothers in Ethiopia had low BMI ( $\left.<18.5 \mathrm{~kg} / \mathrm{m}^{2}\right)$ compared to only seven percent in Zambia. Both countries have a very high, and comparable, prevalence of stunting (45-46 \%), although the prevalence of underweight and wasting is more than twice as high in Ethiopia as it is in Zambia.

\section{Distribution of IYCF practices}

Key IYCF indicators are compared between the two countries in Table 3. Breastfeeding related practices were somewhat similar in both countries, with a high percentage of children still being breastfed around the age of 12-15 months, and rates of exclusive breast-feeding (EBF) well below desired levels at $43 \%$ in Ethiopia and $51 \%$ in Zambia. 


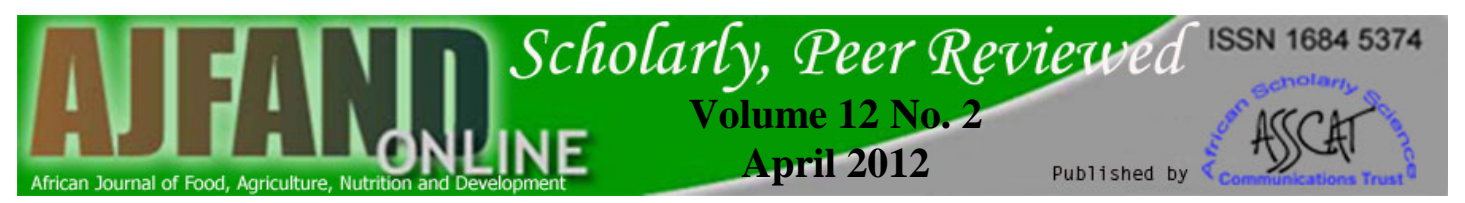

Complementary feeding practices varied substantially between the two countries. Timely introduction of complementary food was high in Zambia at $90 \%$ compared to Ethiopia where only $60.7 \%$ children received complementary food at the recommended age. All other complementary feeding indicators, although low in both countries, were significantly lower in Ethiopia, where several practices (minimum diet diversity, minimum acceptable diet, and consumption of iron-rich food) were observed in less than ten percent of children aged 6-23 months.

\section{Patterns of child nutrition}

Figure 1 and Figure 2 depict the trends in undernutrition indicators (HAZ, WHZ and WAZ) in Ethiopia and Zambia, respectively, among children 0-59 months old. The patterns of the undernutrition by age were similar in both countries, except for agetrends in WAZ. In Ethiopia, all three indicators of undernutrition start declining immediately after birth, upto the age of six months. HAZ and WAZ decline more sharply compared to WHZ in this period. WAZ and WHZ appear to level off after 6 months of age, but HAZ shows a steady decline from birth until approximately 20 months of age, after which HAZ scores plateau at about -2 to -2.5 SD below median until 59 months of age. After an initial decline in the earlier months after birth, WHZ plateaus and then again rises at around 21-23 months. WAZ continued to be at -1.5 SD below the reference median throughout the period. In Zambia, WAZ and HAZ started declining immediately at birth but not WHZ. Unlike Ethiopia, the decline for WAZ was not as steep and remained between $-0,5$ to- 1 SD below the median. WHZ remained between zero to $+0.5 \mathrm{SD}$ above the median until 59 months of age. HAZ declines until 18-20 months of age and rises slightly at 21-23 months before leveling off thereafter at -2 SD below the median. The WAZ by age patterns in Zambia are more congruent with global patterns of child undernutrition than the WAZ by age pattern in Ethiopia. 

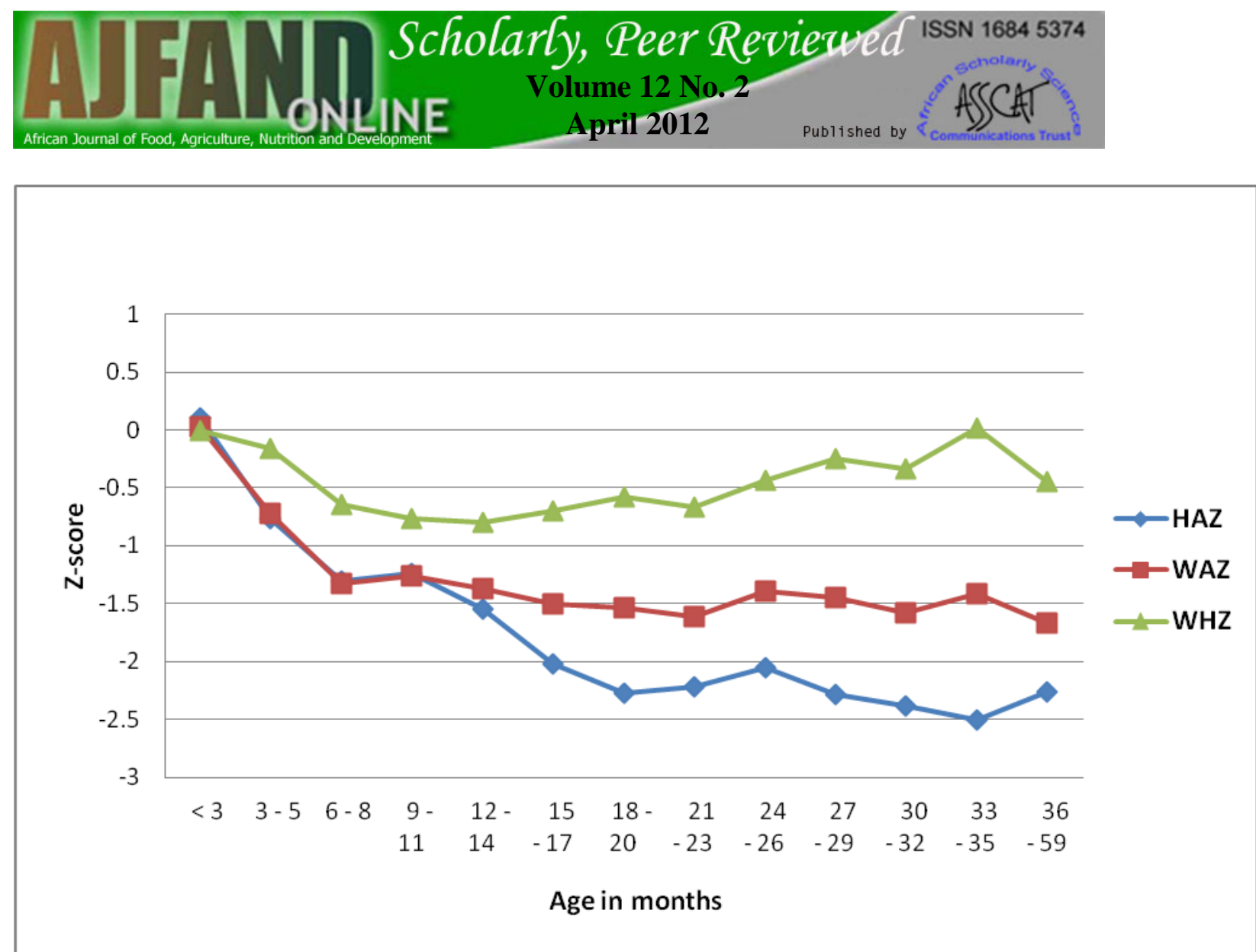

Figure 1: Height-for-age (HAZ), weight-for-age (WAZ), and weight-for-height Zscores (WHZ), by age, among children 0-59 months old in Ethiopia

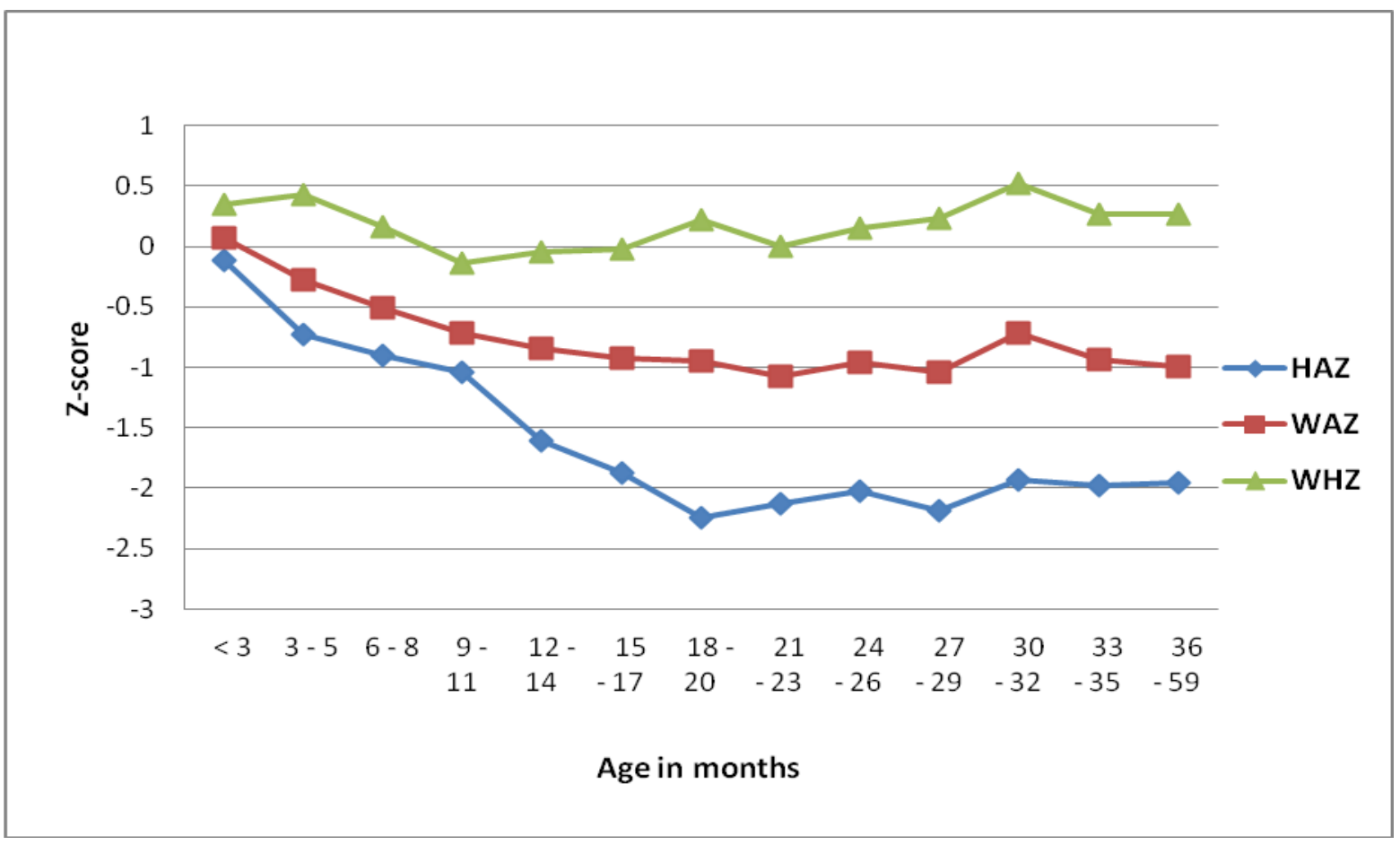

Figure 2: Height-for-age (HAZ), weight-for-age (WAZ), and weight-for-height Zscores (WHZ), by age, among children 0-59 months old in Zambia 


\section{Association between key IYCF practices and undernutrition}

Table 4 summarizes the coefficients for the regression models that examined the association between the key IYCF indicators and child undernutrition. Exclusive breast-feeding was found to be negatively associated with HAZ in Ethiopia at a statistically significant level; there was no significant association in Zambia. EBF was positively associated with WAZ and WHZ in Zambia and with WHZ in Ethiopia. Continued breast-feeding was negatively associated with HAZ and WAZ in both countries. Infant young and child feeding practices related to complementary feeding were positively and significantly $(\mathrm{p}<0.05)$ associated with undernutrition indicators, particularly HAZ. Timely introduction of solid, semisolid or soft food was significantly associated with higher HAZ in Zambia but not in Ethiopia. Diet diversity was strongly associated with HAZ in both countries. Minimum diet diversity (4+ food groups versus $<4$ ) was significantly associated with HAZ in Zambia but only marginally associated with HAZ in Ethiopia $(\mathrm{p}<0.10)$. The weak association between minimum dietary diversity and HAZ in Ethiopia is likely due to the very small proportion $(7.1 \%)$ of children who meet minimum dietary diversity. Minimum acceptable diet was positively associated with HAZ and WAZ in both countries, but not with WHZ.

Table 5 presents OLS regression models for diet diversity and HAZ, WAZ, and WHZ in both countries. Both in Ethiopia and Zambia, male children have shown to have significantly lower Z-scores for all three anthropometric indicators compared to their female counterparts. Mothers who completed secondary school were more likely to have children with higher WAZ and WHZ but not HAZ in both countries. Urban versus rural residence was not associated with any anthropometric indicator in either country. Socio-economic condition as measured by wealth quintile showed a marginal effect on the undernutrition outcomes. Being breastfed at the time of survey was negatively associated with HAZ and WAZ in both countries $(\mathrm{p}<0.01$ and $\mathrm{p}<0.05$, respectively). The number of children living in a household was strongly and negatively associated with HAZ and WAZ in Ethiopia but not in Zambia. Maternal height showed a significant positive relationship with HAZ and WAZ in Ethiopia and body mass index (BMI) was also found to be significantly associated with WAZ and WHZ in Ethiopia. Baby birth size, as perceived by mothers, was seen to be associated with nutritional status of the children. Compared to average size at birth, children who were perceived to be smaller at birth showed significant negative associations with WAZ and WHZ in Ethiopia. In Zambia, this association was observed for HAZ and WAZ. Mean HAZ, WAZ, and WHZ scores, by diet diversity, adjusted for child, maternal, $\mathrm{HH}$, and regional level characteristics are presented in Figure 3. Ethiopian children, who consume an adequately diverse diet, have a 0.3 higher HAZ compared to children that do not consume an adequately diverse diet $(\mathrm{p}<0.05)$; in Zambia, this difference in HAZ was $0.15(\mathrm{p}<0.05)$. 

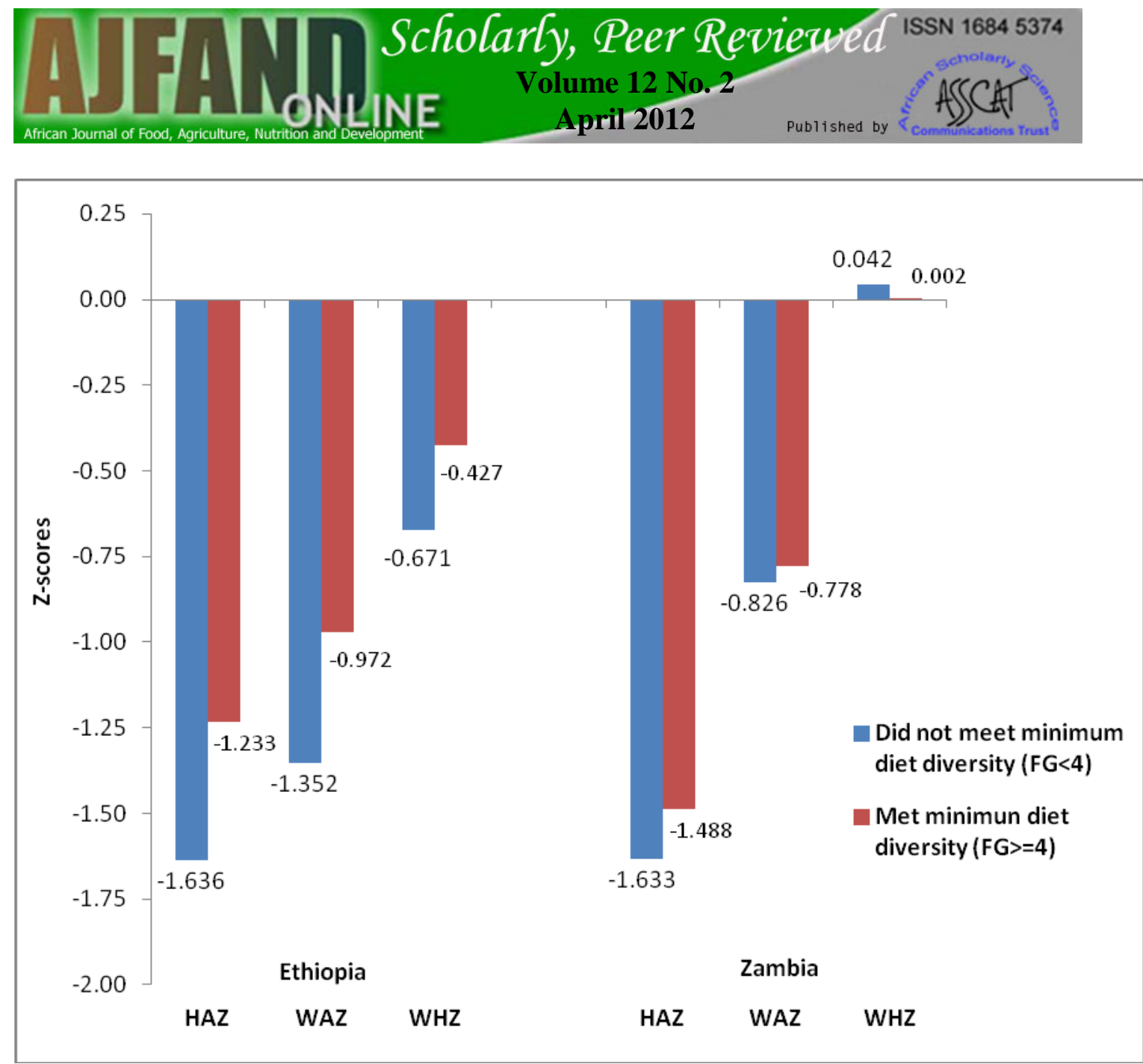

Figure 3: Adjusted mean HAZ, WAZ and WHZ, by minimum diet diversity, in Ethiopia and Zambia

\section{DISCUSSION}

Using nationally representative data, this study examined the association between WHO-recommended key IYCF practices in Ethiopia and Zambia and indicators of child undernutrition. All key IYCF practices were suboptimal in both countries, barring continued breast-feeding at 12-15 months. In particular, complementary feeding practices were alarmingly poor in Ethiopia among children aged 6-23 months old. Overall, the associations between IYCF indicators and child anthropometry were mixed in both countries with complementary feeding practices showing stronger and more positive associations with child anthropometry than breast-feeding practices.

Exclusive breast-feeding was negatively associated with child HAZ in Ethiopia but not Zambia; continued breast-feeding at 12-15 months of age was negatively associated with HAZ in both countries. Among complementary feeding indicators, there was a strong positive association between introduction of solid and semi-solid foods between 6-8 months of age and HAZ in Zambia, but not in Ethiopia. In both countries, among children 6-23 months of age, having adequate dietary diversity, consumption of a minimally acceptable diet, and consumption of iron-rich foods were 
positively associated with HAZ. Meal frequency was positively associated with HAZ only in Ethiopia.

The observed negative association between EBF and HAZ in Ethiopia has been seen before in the literature $[15,16]$. However, the magnitude of the coefficient is unexpectedly large compared to what has been seen in other contexts. In other analyses of DHS data sets from India and Bangladesh, a negative (but not significant) association was seen between EBF and HAZ. A study in India found no association between EBF and undernutrition rates in India [15], while a study in Bangladesh found a positive association between EBF and undernutrition [16]. The main interpretation of this result is not that EBF is unimportant for nutrition and health consequences in Ethiopia, but rather that the measurement of EBF and maternal decisions related to EBF need further study in this context. The 24-hr recall method of measuring EBF in surveys, while considered a valid indicator, does not capture the history of EBF for a specific infant over the first six months of life. A definitive answer to the question of the extent to which EBF is supportive of better linear growth in this context, therefore, can only be obtained through a longitudinal cohort study that tracks EBF and linear growth patterns closely.

The negative association between continued breast-feeding and HAZ that was observed in both Ethiopia and Zambia supports early findings in similar settings $[17,18,19]$. In several sub-Saharan African countries it was observed that the nutritional status of children 12-18 months of age who were still breastfed was poor relative to those who were no longer breast-feeding in that age group. However, among older children in most of these countries, the nutritional status of the two groups was comparable, and, in some countries, a trend towards better nutritional status was observed for those breastfed the longest [19]. The authors of this study postulate that the observed relationship between continued breast-feeding and child size is due to reverse causality and is related to a mother's decision to continue to breastfeed vulnerable children without introducing appropriate foods. The results confirm a significant negative association between prolonged or continued breastfeeding in children 12-15 months of age with HAZ, in line with this finding. The study is unable to confirm the reverse among older children 30-36 months of age as our sample only included children less than 24 months of age.

The analyses for this study demonstrate a strong association between dietary diversity and HAZ in both countries, after controlling for maternal, child, household, and regional level characteristics, in line with previous findings in Ethiopia [7] and elsewhere [8]. Using data from 11 DHS surveys in sub-Saharan Africa, Asia and Latin America, Arimond and Ruel found that consuming an adequately diverse diet was associated with a higher HAZ among children aged 6-23 months [7]. Similarly, in rural Bangladesh, Rah et al [8] demonstrated that reduced dietary diversity was a strong predictor of stunting among children $<60$ months of age; compared with low dietary diversity, high dietary diversity was associated with a $15 \%$, $26 \%$ and $31 \%$ reduced odds of being stunted among children aged 6-11, 12-23 and 24-59 months, respectively. Neither of these studies used the new WHO recommended dietary diversity indicator (or other IYCF indicators) and to our knowledge, our study is the 
first to demonstrate the association between dietary diversity and HAZ in Zambia. Given our finding of an association between dietary diversity and HAZ, it is unsurprising to see a similar association with the minimal acceptable diet indicator, which is a composite indicator of diet diversity and meal frequency.

The study also identified some factors other than IYCF that are associated with undernutrition. Boys were more likely to be stunted and underweight than girls, a finding, also observed in other studies in Ethiopia and other African countries $[20,21,22]$. This vulnerability of male children is unlikely to be the result of gender preference or preferential feeding practices because female infants usually receive less food than male infants $[20,23]$. Thus, the poorer anthropometric status of male infants may simply indicate a greater biological vulnerability of male infants at young ages. Wells [24] suggests that despite the improvement in medical care, environmental stresses have harsher effects on males than females in early life.

Strong associations were observed between maternal characteristics and child nutritional status. Mothers who had completed secondary school were more likely to have children with higher WAZ and WHZ, similar to other studies [25,26]. Maternal height and BMI were strongly associated with most of the undernutrition indicators. This association was also previously found in Ethiopia and in Zambia [7,27,28]. This re-emphasizes the need for a focus on maternal nutritional status as intergenerational malnutrition is known to affect child growth [29]. In this study, the perceived birth size of the children reported by the mothers showed an association with the nutritional status of the children in the expected direction. Although there is no published literature showing the association between perceived birth size and anthropometric outcomes at later ages, it serves as a useful proxy in the absence of robust data on low birth weight, which is a known major predictor of stunting [19]. In both data sets, household wealth, as captured by the DHS asset-based wealth measure, did not have a clear association with nutritional status. While somewhat surprising, this could be an outcome of overall high levels of poverty, and a lower variability of the wealth status of households when compared to other contexts. As with the household wealth measure, there were no urban-rural differences in either country. This could, again, be a reflection of lower variability in the contextual determinants of child growth between urban and rural environments in two countries. Arimond and Ruel in their multi-country analyses did not see such differences in all the countries for which they conducted their analyses [7].

A limitation of this study is the cross-sectional nature of the data used for our analysis which prevents us from determining causality. However, the use of nationally representative data lends strength and credibility to our analyses. In addition, several potential confounders at multiple levels were controlled for in the analyses by the inclusion of child, maternal, household and regional level characteristics, as well as statistical adjustments for the complex survey designs. Longitudinal studies are needed to carefully track child IYCF practices throughout the period from birth to 24 months of age, and causally link these practices with individual child growth patterns. In the absence of such resource-intensive studies, the use of national data sets like the DHS to identify policy and program priorities is highly appropriate.

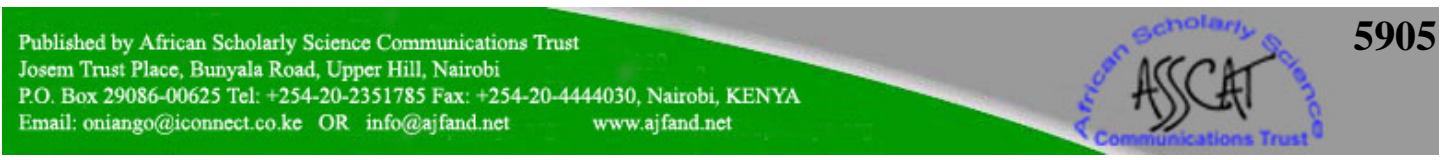




\section{CONCLUSION}

Drawing results from Ethiopia and Zambia, this study has demonstrated that optimal IYCF practices are critical for nutritional status of young children. In both the countries, practices related to complementary feeding were associated with HAZ and WAZ (stunting and underweight), more consistently with stunting. The findings and interpretation of results related to breast-feeding practices are not quite straightforward. While a strong positive effect of exclusive breast-feeding was observed on underweight and wasting in Zambia, this was not seen in Ethiopia. The findings of this analysis provide a basis for programmatic interventions that ensure a focus on complementary feeding while also sustaining a focus on EBF, if improvements in chronic malnutrition in these countries are to be achieved. In subSaharan Africa, given the strong association between EBF and mortality and the high infant mortality rates in the region, interventions focused on promoting EBF have been normative and widespread for many years. However, it is now well known that beyond the age of 6 months, a diet of breast milk alone is inadequate to maintain child growth and development, and that adequate complementary feeding is critical [30]. Thus, interventions addressing the full spectrum of infant and young child feeding are essential, from birth until 24 months of age, to reduce infant mortality as well as to improve overall undernutrition rates. While there remains scope for improvements in breast-feeding practices, the gap in adequate complementary feeding practices is even larger than in EBF in these countries and needs urgent attention if undernutrition rates are to decline.

\section{ACKNOWLEDGEMENTS}

We gratefully acknowledge feedback from Luann Martin, Alive \& Thrive, FHI360 and Veronica Lee, an intern with Alive \& Thrive Ethiopia program, for her contribution to the literature review for this paper. 
Table 1: Definitions of WHO-recommended core Infant and Young Child Feeding (IYCF) indicators

\begin{tabular}{ll}
\hline \multicolumn{1}{c}{ Indicators } & \multicolumn{1}{c}{ Definition } \\
\hline Early initiation of breast feeding & $\begin{array}{l}\text { Proportion of children born in the last 24 months who } \\
\text { were put to the breast within one hour of birth }\end{array}$ \\
$\begin{array}{l}\text { Exclusive breast-feeding under } 6 \\
\text { months }\end{array}$ & $\begin{array}{l}\text { Proportion of infants 0-5 months of age who are fed } \\
\text { exclusively with breast milk }\end{array}$ \\
$\begin{array}{l}\text { Continued breast-feeding at } 1 \\
\text { year }\end{array}$ & $\begin{array}{l}\text { Proportion of children 12-15 months of age who are } \\
\text { fed breast milk }\end{array}$ \\
$\begin{array}{l}\text { Introduction of solid, semi-solid } \\
\text { or soft foods }\end{array}$ & $\begin{array}{l}\text { Proportion of infants 6-8 months of age who receive } \\
\text { solid, semi-solid or soft foods }\end{array}$ \\
Minimum dietary diversity & $\begin{array}{l}\text { Proportion of children 6-23 months of age who receive } \\
\text { foods from 4 or more food groups }\end{array}$ \\
Minimum meal frequency & $\begin{array}{l}\text { Proportion of breastfed and non-breastfed children 6-23 } \\
\text { months of age, who receive solid, semi-solid, or soft } \\
\text { foods (but also including milk feeds for non-breastfed } \\
\text { children) the minimum number of times or more }\end{array}$ \\
$\begin{array}{l}\text { Consumption of iron-rich/iron- } \\
\text { fortified food for children 6-23 } \\
\text { months }\end{array}$ & $\begin{array}{l}\text { Proportion of children 6-23 months of age who receive } \\
\text { a minimum acceptable diet (apart from breast milk) }\end{array}$ \\
\hline $\begin{array}{l}\text { Proportion of children 6-23 months of age who receive } \\
\text { animum acceptable diet }\end{array}$ & $\begin{array}{l}\text { fesigned for infants and young children, or that is } \\
\text { fortified in the home. }\end{array}$ \\
\hline
\end{tabular}




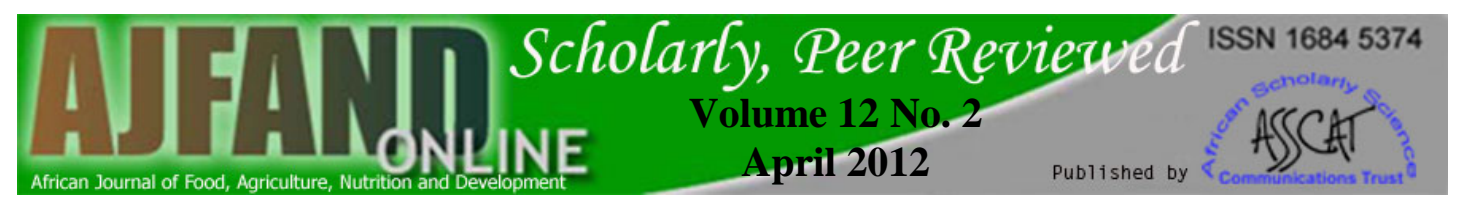

Table 2: Distribution of $\mathrm{HH}$, maternal and child characteristics in Zambia and Ethiopia

\begin{tabular}{|c|c|c|c|c|}
\hline \multirow[b]{2}{*}{ Characteristics } & \multicolumn{2}{|c|}{ Ethiopia } & \multicolumn{2}{|c|}{ Zambia } \\
\hline & $\%$ & $\mathrm{n}$ & $\%$ & $\mathrm{~N}$ \\
\hline \multicolumn{5}{|l|}{ Child (0-23 months) } \\
\hline Stunted $($ HAZ $<-2)$ & 46.6 & 1079 & 45.4 & 1653 \\
\hline Underweight (WAZ<-2) & 33.4 & 1079 & 15.5 & 1653 \\
\hline Wasted $(\mathrm{WHZ}<-2)$ & 17.1 & 1079 & 7.4 & 1653 \\
\hline \multicolumn{5}{|l|}{ HH characteristics } \\
\hline Rural & 92.6 & 1810 & 71.5 & 2512 \\
\hline Female-headed & 11.3 & & 16.3 & \\
\hline Piped water & 5.7 & & 10.5 & \\
\hline No sanitation facility & 66.5 & & 26.8 & \\
\hline Electricity & 7.2 & & 13.8 & \\
\hline \multicolumn{5}{|l|}{ Wealth quintile } \\
\hline Poorest & 22.6 & & 24.1 & \\
\hline Poorer & 21.0 & & 22.8 & \\
\hline Middle & 21.3 & & 21.2 & \\
\hline Richer & 20.6 & & 18.4 & \\
\hline Richest & 14.3 & & 13.5 & \\
\hline Maternal height (cm) & 156.5 & 1810 & 166.3 & 2512 \\
\hline \multicolumn{5}{|l|}{ Maternal BMI } \\
\hline$<18.5 \mathrm{~kg} / \mathrm{m} 2(\%)$ & 20.1 & & 7.6 & \\
\hline$>25 \mathrm{~kg} / \mathrm{m} 2(\%)$ & 3.5 & & 16.7 & \\
\hline Education & & 1810 & & \\
\hline No education & 77.2 & & 13.7 & \\
\hline Completed primary & 18.1 & & 63.7 & \\
\hline $\begin{array}{l}\text { Completed secondary and } \\
\text { tertiary }\end{array}$ & 4.6 & & 22.6 & \\
\hline Prenatal care use & & 1761 & & 2512 \\
\hline No prenatal visit & 70.7 & & 2.2 & \\
\hline $1-3$ visits & 17.2 & & 37.1 & \\
\hline$>3$ visits & 12.8 & & 60.8 & \\
\hline
\end{tabular}


Table 3: Comparison of IYCF Indicators across the two countries

\begin{tabular}{lcccc}
\hline \multicolumn{1}{c}{ Indicators } & \multicolumn{2}{c}{ Ethiopia } & \multicolumn{2}{c}{ Zambia } \\
\cline { 2 - 5 } & \% & n & \% & n \\
\hline $\begin{array}{l}\text { Early initiation of breast-feeding } \\
\text { for children 0-24 months }\end{array}$ & 66.9 & 1810 & 56.2 & 2512 \\
$\begin{array}{l}\text { Exclusive breast-feeding under 6 } \\
\text { months }\end{array}$ & 43.0 & 585 & 51.4 & 719 \\
$\begin{array}{l}\text { Continued breast-feeding for } \\
\text { children 12-15 months }\end{array}$ & 94.8 & 430 & 93.1 & 516 \\
$\begin{array}{l}\text { Introduction of solid, semisolid or } \\
\text { soft food for infants 6-8 months }\end{array}$ & 60.7 & 244 & 90 & 344 \\
$\begin{array}{l}\text { Minimum diet diversity for } \\
\text { children 6-23 months } \geq \mathbf{4} \text { food } \\
\text { groups) }\end{array}$ & 7.1 & 1227 & 37.4 & 1793 \\
$\begin{array}{l}\text { Minimum meal frequency for } \\
\text { children 6-23 months }\end{array}$ & 54.7 & 1116 & 56.3 & 1445 \\
$\begin{array}{l}\text { Minimum acceptable diet for } \\
\text { children 6-23 months }\end{array}$ & 5.2 & 1116 & 25.1 & 1445 \\
$\begin{array}{l}\text { Consumption of iron-rich/iron- } \\
\text { fortified food for children 6-23 } \\
\text { months }\end{array}$ & 8.9 & 1227 & 59.5 & 1793 \\
\hline
\end{tabular}




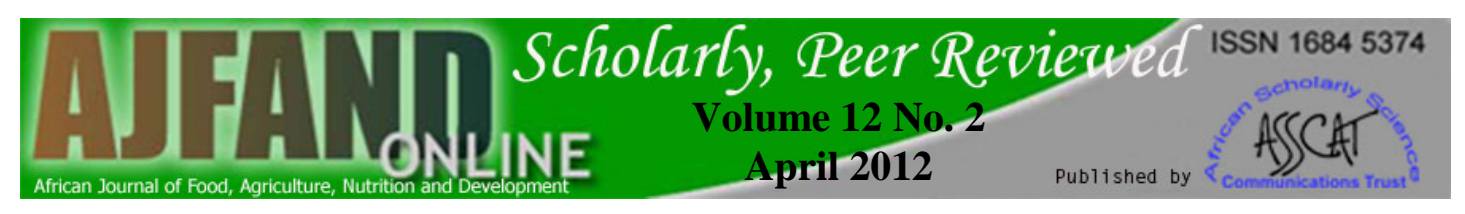

Table 4: Association between IYCF indicators and child HAZ, WAZ, WHZ in Ethiopia and Zambia (regression coefficients from different OLS regression models)

\begin{tabular}{|c|c|c|c|c|c|c|c|c|}
\hline \multirow[b]{2}{*}{ Indicators } & \multicolumn{4}{|c|}{ Ethiopia } & \multicolumn{4}{|c|}{ Zambia } \\
\hline & HAZ & WAZ & $\begin{array}{c}\text { WH } \\
\mathbf{Z}\end{array}$ & $\mathbf{n}$ & HAZ & WAZ & $\begin{array}{c}\text { WH } \\
\text { Z }\end{array}$ & $\mathbf{n}$ \\
\hline $\begin{array}{l}\text { Early initiation of } \\
\text { breast-feeding for } \\
\text { children } 0-24 \text { months }\end{array}$ & -0.12 & $-0.20^{*}$ & $-0.2^{+}$ & $\begin{array}{c}143 \\
6\end{array}$ & 0.00 & 0.06 & 0.10 & 2133 \\
\hline $\begin{array}{l}\text { Exclusive breast-feeding } \\
\text { under } 6 \text { months }\end{array}$ & $0.80^{* *}$ & -0.26 & $0.53^{+}$ & 391 & -0.25 & $0.28^{*}$ & $0.65^{*}$ & 553 \\
\hline $\begin{array}{l}\text { Continued breast- } \\
\text { feeding in children 12- } \\
15 \text { months }\end{array}$ & $1.66^{* *}$ & $-0.81^{*}$ & -0.06 & 374 & $-1.35^{*}$ & $-0.59^{+}$ & 0.03 & 464 \\
\hline $\begin{array}{l}\text { Introduction of solid, } \\
\text { semisolid or soft food } \\
\text { for infants 6-8 months }\end{array}$ & 0.43 & 0.38 & 0.18 & 216 & $1.19^{* *}$ & -0.09 & $0 . \overline{9} 4^{*}$ & 300 \\
\hline Dietary diversity score & $0.23^{* *}$ & $0.17^{* *}$ & 0.07 & $\begin{array}{c}104 \\
5\end{array}$ & $0.12^{* *}$ & $0.04^{+}$ & -0.03 & 1580 \\
\hline $\begin{array}{l}\text { Minimum diet diversity } \\
\text { for children 6-23 } \\
\text { months }\end{array}$ & $0.40^{+}$ & $0.37^{*}$ & 0.23 & $\begin{array}{c}104 \\
5\end{array}$ & $0.23^{*}$ & 0.09 & -0.04 & 1580 \\
\hline $\begin{array}{l}\text { Minimum meal } \\
\text { frequency for children } \\
6-23 \text { months }\end{array}$ & $0.26^{+}$ & $0.17^{+}$ & 0.05 & 961 & 0.15 & 0.14 & 0.08 & 1274 \\
\hline $\begin{array}{l}\text { Minimum acceptable } \\
\text { diet for children 6-23 } \\
\text { months }\end{array}$ & $0.43^{*}$ & $0.48^{*}$ & 0.34 & 961 & $0.27^{*}$ & $0.17^{*}$ & 0.04 & 1274 \\
\hline $\begin{array}{l}\text { Consumption of iron- } \\
\text { rich/iron-fortified food } \\
\text { for children } 6-23 \\
\text { months }\end{array}$ & $0.52^{+}$ & $0.32^{+}$ & 0.07 & $\begin{array}{c}104 \\
5\end{array}$ & $0.13^{+}$ & 0.13 & 0.07 & 1580 \\
\hline
\end{tabular}

$+p<0.10,{ }^{*} p<0.05,{ }^{* *} p<0.01,{ }^{* * *} p<0.001$ 


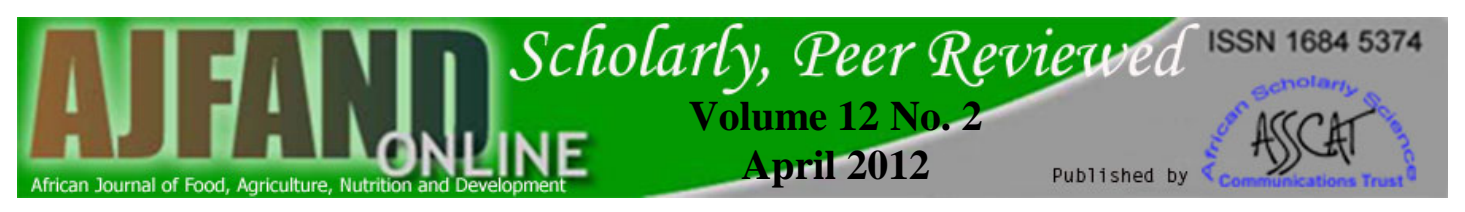

Table 5: Regression models for association between diet diversity and HAZ, WAZ, and WHZ in Ethiopia and Zambia

\begin{tabular}{|c|c|c|c|c|c|c|}
\hline \multirow[b]{2}{*}{ Characteristics } & \multicolumn{3}{|c|}{ Ethiopia } & \multicolumn{3}{|c|}{ Zambia } \\
\hline & HAZ & WAZ & WHZ & HAZ & WAZ & WHZ \\
\hline Diet diversity score & $0.22^{* * *}$ & $0.14^{* *}$ & 0.04 & $0.12^{* *}$ & 0.04 & -0.03 \\
\hline Age & -0.07 & -0.02 & -0.11 & $-0.15^{*}$ & $-0.07^{+}$ & $-0.11^{*}$ \\
\hline Age-squared & 0.00 & 0.00 & 0.00 & 0.00 & 0.00 & $0.00^{*}$ \\
\hline Gender (reference - female) & $0.51^{-}$ & $-0.40^{* * *}$ & $-0.22^{+}$ & $-0.26^{*}$ & $0.2^{-}$ & $-0.14^{+}$ \\
\hline Maternal height & $0.04^{* *}$ & $0.03^{* * *}$ & 0.00 & 0.01 & 0.00 & 0.00 \\
\hline Maternal BMI & 0.01 & $0.04^{*}$ & $0.05^{*}$ & 0.00 & 0.02 & 0.02 \\
\hline \multicolumn{7}{|l|}{ Maternal education } \\
\hline \multicolumn{7}{|l|}{ None (ref) } \\
\hline Completed primary & 0.10 & 0.19 & 0.15 & $-0.31^{*}$ & 0.03 & $0.25^{*}$ \\
\hline $\begin{array}{l}\text { Completed secondary \& } \\
\text { higher }\end{array}$ & -0.1 & $0.43^{*}$ & $0.62^{* *}$ & -0.19 & $0.2^{+}$ & $0.4^{* *}$ \\
\hline \multicolumn{7}{|l|}{ Utilization of antenatal care } \\
\hline $1-3$ visits & -0.26 & 0.01 & 0.2 & 0.02 & 0.3 & 0.3 \\
\hline$>3$ visits & -0.11 & 0.08 & 0.15 & 0.11 & 0.22 & 0.14 \\
\hline Residence (reference- rural) & 0.13 & 0.3 & 0.34 & 0.51 & 0.25 & 0.01 \\
\hline \multicolumn{7}{|l|}{ Wealth quintile } \\
\hline \multicolumn{7}{|l|}{ Quintile 1 (ref) } \\
\hline Quintile 2 & -0.21 & $-0.24^{+}$ & -0.19 & $0.23^{+}$ & 0.052 & -0.1 \\
\hline Quintile 3 & -0.11 & 0.05 & 0.11 & $0.22^{+}$ & 0.1 & -0.03 \\
\hline Quintile 4 & 0.07 & 0.22 & 0.24 & 0.29 & 0.07 & -0.15 \\
\hline Quintile 5 & 0.07 & 0.05 & 0.00 & 0.25 & 0.02 & -0.19 \\
\hline Currently breastfed & $-1.32^{* * *}$ & $-0.72^{* *}$ & -0.1 & $0.79^{* * *}$ & $-0.3^{* *}$ & 0.12 \\
\hline Number of children & $-0.32^{* *}$ & $-0.23^{* *}$ & -0.08 & -0.00 & -0.03 & -0.04 \\
\hline \multicolumn{7}{|l|}{ Birth Size } \\
\hline \multicolumn{7}{|l|}{ Average(ref) } \\
\hline Very large & -0.05 & 0.06 & 0.09 & 0.23 & $0.25^{+}$ & 0.19 \\
\hline Larger than average & 0.27 & 0.19 & 0.02 & $0.26^{*}$ & $0.12^{+}$ & 0.00 \\
\hline Smaller than average & 0.05 & $-0.41^{*}$ & $-0.57^{*}$ & -0.19 & $-0.26^{*}$ & -0.21 \\
\hline Very small & -0.20 & $-0.42^{* * *}$ & $-0.42^{* *}$ & $-1.4^{* * *}$ & $1.25^{-}$ & -0.6 \\
\hline $\mathbf{R}^{2}$ & 0.19 & 0.24 & 0.13 & 0.15 & 0.11 & 0.06 \\
\hline F-statistics & 7.16 & 11.88 & 5.35 & 6.13 & 4.14 & 3.00 \\
\hline
\end{tabular}




\section{REFERENCES}

1. Black RE, Allen LH, Bhutta ZA, Caulfield LE, de Onis M, Ezzati M, Mathers $\mathbf{C}$ and $\mathbf{J}$ Rivera Maternal and child undernutrition: global and regional exposures and health consequences. Lancet 2008; 371(9608):243260.

2. Ezzati M, Lopez AD, Rodgers A, Vander Hoorn S and CJ Murray Selected major risk factors and global and regional burden of disease. Lancet 2002; 360: 1347-1360.

3. Victora CG, Adair L, Fall C, Hallal PC, Martorell R, Richter L and HS Sachdev Maternal and child undernutrition: consequences for adult health and human capital. Lancet 2008; 371(9609): 340 -357.

4. Hatløy A, Hallund J, Diarra MM and A Oshaug Food variety, socioeconomic status and nutritional status in urban and rural areas in Koutiala (Mali). Public Health Nutr 2000; 3(1):57-65.

5. Agee MD Reducing child malnutrition in Nigeria: Combined effects of income growth and provision of information about mothers' access to health care services. Soc Sci Med 2010; 71(11): 1973-1980 .

6. Kanjilal B, Mazumdar PG, Mukherjee M and MH Rahman Nutritional status of children in India: household socio-economic condition as the contextual determinant. Int J Equity Health 2010; 9(1):19.

7. Arimond $\mathbf{M}$ and MT Ruel Dietary diversity is associated with child nutritional status: evidence from 11 Demographic and Health Surveys. J Nutr 2004; 134(10):2579-2585.

8. Rah JH, Akhter N, Semba RD, Pee SD, Bloem MW, Campbell AA, Moench-Pfanner $\mathbf{R}$, Sun $\mathbf{K}$, Badham $\mathbf{J}$ and $\mathbf{K}$ Kraemer Low dietary diversity is a predictor of child stunting in rural Bangladesh. Eur J Clin Nutr 2010; 64(12): 1393-1398.

9. World Health Organization. Indicators for assessing infant and young child feeding practices. Geneva: World Health Organization. 2008

10. Ruel MT Is dietary diversity an indicator of food security or dietary quality? A review of measurement issues and research needs. Food Nutr Bull 2003; 24(2):231-2.

11. Shrimpton R, Victora CG, de Onis M, Lima RC, Blossner M and G Clugston Worldwide timing of growth faltering: implications for nutritional interventions. Pediatrics 2001; 107(5): 1-7. 
12. Central Statistical Agency [Ethiopia] and ORC Macro. Ethiopia Demographic and Health Survey 2005. Addis Ababa, Ethiopia and Calverton, Maryland, USA: Central Statistical Agency and ORC Macro. http//www.measuredhs.com/pubs/pdf/FR179/FR179.pdf Accessed November, 2009.

13. Central Statistical Office (CSO), Ministry of Health (MOH), Tropical Diseases Research Centre (TDRC), University of Zambia, and Macro International Inc. Zambia Demographic and Health Survey 2007. Calverton, Maryland, USA: CSO and Macro http//www.measuredhs.com/pubs/pdf/FR211/FR211.pdf Accessed March, 2010.

14. World Health Organization. Multicentre Growth Reference Study Group. WHO Child Growth Standards: Length/height-for-age, weight-for-age, weight-for-length, weight-for-height and body mass index-for-age: Methods and development. Geneva: World Health Organization, 2006.

15. Kumar D, Goel NK, Mittal PC and P Misra Influence of infant-feeding practices on nutritional status of under-five children. Indian J Pediatr 2006; 73(5): 417-421.

16. Giashuddin MS, Kabir M, Rahman A and MA Hannan Exclusive breastfeeding and nutritional status in Bangladesh. Indian J Pediatr 2003; 70(6): 471-475.

17. Marquis GS, Habicht JP, Lanata CF, Black RE and KM Rasmussen Association of breast-feeding and stunting in Peruvian toddlers: An example of reverse causality. Int J Epidemiol 1997; 26(2): 349-356.

18. Victora CG, Vaughan JP, Martines JC and LB Barcelos Is prolonged breast-feeding associated with malnutrition? Am J Clin Nutr 1984; 39(2): 307314.

19. Caulfield LE, Bentley ME and S Ahmed Is prolonged breast-feeding associated with malnutrition? Evidence from nineteen demographic and health surveys. Int J Epidemiol 1996; 25(4): 693-703.

20. Medhin G, Hanlon C, Dewey M, Alem A, Tesfaye F, Worku B, Tomlinson $\mathbf{M}$ and $\mathbf{M}$ Prince Prevalence and predictors of undernutrition among infants aged six and twelve months in Butajira, Ethiopia: the P-MaMiE Birth Cohort. BMC Public Health 2010; 10: 27.

21. Getahun Z, Urga K, Ganebo $\mathbf{T}$ and A Nigatu Review of the status of malnutrition and trends in Ethiopia. Ethiop J Health Dev 2001; 15(2): 55-74.

22. Wamani H, Åstrøm AN, Peterson S, Tumwine JK and T Tylleskär Boys are more stunted than girls in Sub-Saharan Africa: A meta-analysis of 16 demographic and health surveys. BMC Pediatr 2007; 7: 17-26. 
23. Hadley C, Lindstrom D, Tessema F and $\mathbf{T}$ Belachew Gender bias in the food insecurity experience of Ethiopian adolescents. Soc Sci Med. 2008; 66: 427-438.

24. Wells JC Natural selection and sex differences in morbidity and mortality in early life. $J$ Theor Biol 2000; 202: 65-76.

25. Genebo $\mathbf{T}$, Girma $\mathbf{W}$, Haider $\mathbf{J}$ and $\mathbf{T S}$ Demisse The association of children's nutritional status to maternal education in Zigbaboto, Guragie Zone. Ethiop J Health Dev 1999; 13: 55-61.

26. Yimer G Malnutrition among children in Southern Ethiopia: levels and risk factors. Ethiop J Health Dev 2000; 14: 283-292.

27. Gibson RS, Abebe Y, Hambidge KM, Arbide I, Teshome A and BJ Stoecker Inadequate feeding practices and impaired growth among children from subsistence farming households in Sidama, Southern Ethiopia. Matern Child Nutr 2009; 5: 260-275 .

28. Hautvast JL, Tolboom JJ, Kafwembe EM, Musonda RM, Mwanakasale V, van Staveren WA, van 't Hof MA, Sauerwein RW, Willems JL and LA Monnens Severe linear growth retardation in rural Zambian children: the influence of biological variables. Am J Clin Nutr 2000; 71: 550-559.

29. Dewey KG The challenges of promoting optimal infant growth. J Nutr 2001; 131: $1879-1880$.

30. Pan American Health Organization/World Health Organization. Guiding Principles for Complementary Feeding of the Breast-Fed Child. 2003. http://whqlibdoc.who.int/paho/2003/a85622.pdf. Accessed March, 2010 